\title{
CONTEXTUALIZING LEARNING: BECOMING A TOURISM AND HOSPITALITY PROFESSIONAL
}

\author{
Gayle Jennings \\ Imagine Consulting Group International Pty Ltd
}

\begin{abstract}
Over three years, a final semester, undergraduate project-based tourism and hospitality course was successively refined using action research processes. The course required students to integrate and put into practice learnings from all courses. Each offering of the course required students to develop, implement and evaluate a tourism and hospitality project specifically related to their interests. The majority of students developed projects in conjunction with industry partners, a few with hypothetical industry partners, and several with themselves as entrepreneurs. Initially, role-play was variously used to engage students in experiential profession-based learning. By the third year of offering, role-play was replaced by simulation. Students became a community of practice, wherein each week's face-to-face contact involved a focused round-table departmental meeting. During meetings, there was a strong emphasis on intrapersonal, interpersonal and oral communication skill development. Project assessment involved 5-minute pitches, a written proposal, ethics "test", an oral presentation and a written report. Students were required to self-evaluate all assessment tasks. In addition, students anonymously voted and provided written feedback on the best project pitch, as well as written feedback on all oral presentations. Student involvement in self and peer assessment aided personal reflection and constructive feedback with respect to professional practice.
\end{abstract}

Keywords: action research, community of practice, experiential profession-based learning

\section{Introduction}

By engaging in action research processes over a three year period, learning-teaching engagements in an Australian-based final semester, undergraduate project-based tourism and hospitality course were successively refined in order to support students in becoming tourism and hospitality professionals. While not a capstone course, the elective course, entitled 'Field Project', required students to integrate and put into practice learnings from all previous tourism and hospitality-related courses. Although the delivery methods shifted over the three year period, two constants of the course were the course focus and graduate attribute skill outcomes. First, the course adopted an individual student focus wherein each student was required to develop, implement and evaluate a tourism and hospitality project, specifically, related to her or his interests. Second, students, who enrolled in the course, were also required to apply critical thinking skills, problem solve, be creative and innovative as well as to work independently on a self-directed project with an industry stakeholder. Each 
student had a different project from their peers. Each class contained approximately 25 individual projects. Each year, the course was run in two-hour block workshops. The use of workshop format provided flexibility in learningteaching engagements. By the third year, the workshops involved professional presentations, board meeting discussions and dialogue sessions. For some students, the self-directed nature of the course was challenging. As a consequence, the first six weeks of each semester of the course's delivery were associated with providing scaffolding (Vygotsky, 1978) through sequenced profession-based learning activities, which built upon each other so that students were able to work towards independent learning with regard to their projects. The first six weeks of the course outlined the requirements of the course, the nature and components of a proposal, sustainability, ethics and responsible practice, functions of literature reviews, and the specific role of ethics in project work. The remainder of the course was focussed on student projects to drive the content of the workshops including formal orals and final report writing. Assessment was associated with active participation in weekly workshops, a project proposal including a 5-minute oral pitch as well as a written proposal; an ethics online module, submission of a learning journal based on the module and an ethics "test"; a 10 minute oral project presentation; and a final written project submission.

The key innovations that occurred during the action research period period included (1) the inclusion of a project ethics module, originally in face-to-face mode and finally, in an online delivery mode; (2) profession-based learning processes based around departmental meeting processes using role-play and simulation; and (3) peer and self evaluation by students. These innovations were undertaken to ensure that the translation of theory into practice occurred within real, world learning contexts associated with industry requests for graduates to possess "work ready skills and competencies" (Jennings et.al, 2015). The innovations were also undertaken to engage students in learning-teaching experiences that supported students in becoming tourism and hospitality professionals.

\section{Literature Review}

A number of educational philosophies and practices informed the learningteaching engagements that were designed for the course's workshops. First, was Cambourne's (1984) sociolinguistic-based seven conditions of a supportive learning-teaching environment. These conditions include 'immersion' in real world contexts; 'demonstrations' of real world knowledge, skills and competencies; time for 'approximation' with regard to those knowledges, skills and competencies; provisions of timely 'feedback' on those approximations; opportunities and time to 'practice' the knowledges, skills and competencies; 'expectations' by both students and teacher to be successful; and 'responsibility' for learning vested in the individual students supported by the teacher. Second, communities of practice (Wenger, 1998) were used to re-inforce profession-based learning contexts. Communities of practice link identity (becoming) with practice (doing), meaning (experiences), and community (belonging). Both the workshops and projects were predicated on these principles in order to support profession- 
based learning. The latter being "learning and teaching engagements ... [that are] founded on building a professional culture of praxis in and with the learner. Such profession-based learning experiences ... engender culture -- 'communitas' (belonging) beyond formal learning environments to incorporate "profession" business and industry as well as enhance learning" (Jennings et. al., 2007). Third, role-play approaches (Errington, 1997) were used. Role-plays facilitate students in moving from 'declarative knowledge', the what of facts and processes, to 'procedural knowledge', the 'knowing how' (Taylor, 1999, p.2). Further, role-play facilitates 'two-way communication' between peers as well as between students and teachers (Bergquist \& Phillips, 1975); and increases student participation (Bergquist \& Phillips, 1975; Ruhanen, 2006). Still further, "[t]he role-play method develops greater understanding of the complexity of professional practice and enables students to develop skills to engage in multi-stakeholder negotiations within the controlled environment of the classroom" (Manorom \& Pollock, 2006, p.1). And finally, role-play can add fun and enjoyment (Bergquist \& Phillips, 1975) to learning-teaching experiences. Fourth, simulations of departmental meetings were used to structure learning-teaching contexts for workshops. In this paper, simulations are defined as stylised representations of real world contexts and situations that aim to achieve as close an approximation as possible to those real world contexts and situations. In the course, Field Project, the real world simulations in weeks one to six were departmental meetings and for the remainder of the semester, simulations were based on the industry context in which each student was operating with their project industry partner. These varied and included, for example, stakeholder meetings, conference presentations, research settings, investor group meetings, departmental meetings and public meetings.

\section{Methodology}

Action research (Lewin, 1948; Heron \& Reason, 2008) has long been used in education as a means to change and/or improve educational practice (Kemmis \& McTaggart, 1988). As a research approach, action research situates within a participatory paradigm (Heron \& Reason, 2008). In this paper, over a three-year period, action research was an annual cyclical process in which the Field Project teacher engaged with students and industry partners. The aim of the action research was to constantly refine learning-teaching engagements in the course, Field Project, in order to support students in 'becoming' tourism and hospitality professionals. Specifically, the action research involved cycles of designing learning-teaching strategies, implementing those strategies, observing the strategies and constantly reflecting on how effective the strategies were with students and industry partners. Changes were made along the way as well as following an end point evaluation prior to commencing the next action research cycle (Jennings, Scantelbury and Wolfe, 2009).

\section{Results and Discussion}

As iterated in the methodology section, the aim of the action research was to refine learning-teaching engagements in the course, Field Project, in order to support students in 'becoming' tourism and hospitality professionals. So, across 
the three years, was the action research successively able to achieve its aim? The response to this question is organised around the three innovations noted at the beginning of the paper: project ethics, profession-based workshops; self and peer assessment; as well as an overall reflection on the effectiveness of professionbased learning as a means to support students in 'becoming' tourism and hospitality professionals.

Project ethics was formally introduced to reiterate to students the role of ethical practice in their projects and their professions. While primarily delivered within a modularised learning teaching engagement, reflections on ethics were embedded in all workshop sessions as was sustainability and responsible practice. The face-to face delivery was changed to an online learning engagment. The ethics online module had the following aims:

1. To consider the nature of ethics

2. To situate ethics within broader societal and global contexts

3. To overview different approaches to ethics

4. To reflect on ethical standards

5. To introduce a framework to support ethical thinking

6. To examine codes of conduct

7. To provide an overview of the university's policies and systems.

The learning journal entries associated with the online module were organised around the following questions:

1.0 What is ethics?

1.1 Which approach to ethics do you prefer?

1.2 How do ethics relate to your field of study?

1.3 Are similar standards adhered to in other cultures? Why?

1.4 What did you learn from the above with regard to your field of study?

2.0 Write a code of ethics for your field of study.

The online ethics module was followed by a project ethics "test". In line with Australian Vice-Chancellors' Council changes to university processes regarding research ethics, this course adopted the introduction of a project ethics "test". Students needed to achieve at least $75 \%$ in order for students to engage with industry and in the field. The test was based on two scenarios, which were each followed by nine questions. Multiple choice questions were coupled with short answers wherein students substantiated the multiple choices they had made. The final part of each set of questions was a reflection by students regarding the linkages between the scenarios and their own projects. Students who did not achieve $75 \%$ were required to have a debrief session with teacher. The whole of class was provided with feedback on scenarios and answers. The debrief sessions and whole of class discussions served to increase all students' awareness of ethical conduct to $100 \%$. The test also re-enforced that various ethical positions 
may be adopted by people as long as the choice can be justified within existing national protocols.

Student comments regarding the ethics module and the test included:

"You need to be aware of what ethics is and how you can employ them."

"Gained a better understanding of the 'big picture' businesses need to concern themselves with, such as, cultural and social responsibilities."

"I learned the importance of project ethics and the responsibilities of both the client and consultant."

"Assisted me in understanding and developing professional and ethical standards to guide me through my future career."

"Made me realise that ethics certainly play a role when questioning responsible practice."

The course moved from a formal workshop mode to a series of professionbased workshop sessions. At the commencement of the semester, students were informed that the class would be profession-based and why. Specifically,the students were informed that the course aimed to draw on and further develop student skills, knowledges and practices towards the professions into which they would enter. In particular, learning and teaching engagements were to be founded on building a professional culture of praxis in and with the students. Subsequently, each workshop was to run as an organisational meeting wherein each student was a representative from a division or unit within "our" generic and flexible organisation. Students engaged in dialogue with each other and the course convenor/teacher was the CEO. This proved to be extremely effective as students adopted peer responsibility as well as responsible conduct. If students were unable to attend a workshop session, the convenor was informed by email and/or telephone. Absences were always explained. Due to the individualised nature of the projects, the course assessment materials were generically framed so attendance at workshops was important as the course "formal" content was individually tailored to use student projects as examples. Learning assessment tasks were distributed between written (65\%) and oral presentations (35\%). Oral presentations were divided between informal pitches of 5 minutes where students were required to introduce their projects (5\%): what it is; why it needs to be done; how it will be done, and its significance. This was conducted in a rectangular boardroom style. Formal presentations commenced in Week 9 and built on the earlier oral pitches.

Student evaluations of the profession-based workshops reflect the benefits previously stated with respect to using role-plays and simulations, especially, 'two-way communication' between peers as well as between students and teachers (Bergquist \& Phillips, 1975) and increased student participation (Bergquist \& Phillips, 1975; Ruhanen, 2006). The students also recognised the benefits of 'doing' (Wenger, 1998) along with 'immersion', 'practice', 'responsibility' and 'feedback' (Cambourne, 1984) in providing opportunities to change declarative into procedural knowledge (Taylor, 1999). They also expressed enjoyment in 'doing' assignments and participating in the workshops indicating that learning can be fun (Bergquist \& Phillips, 1975) and that theory does apply to practice. 
Student comments now follow:

"This has been one of the most insightful courses included in my degree."

"I enjoyed the assignments and the workshops for this course. The workshops were presented in a professional manner, which really did feel like a meeting rather than being lectured at. The fact that we got to add input and run many sessions made the learning experience more enjoyable, thus a better environment to learn and take in information. It was also good to hear the progress and ideas of other students in the workshop. Hearing their feedback as well as the tutor's and mixing that with my thoughts made the final assignment easier to achieve in terms of length."

"Professional style learning was also a first for me, which I feel was much more advantageous than numerous tutorial classes in that the class really opened up to one another, participated and had a knowledge and concern for other student's work."

"It has been a good learning practice working as a team together to solve problems and hear others perspectives."

"The profession-based approach taken in the workshops was something new, but at the same time was effective. It really helped to set the situation for each workshop, especially during the oral presentations."

"Field Project is a course that is highly based around the principle of "learning by doing". According to Schank, Berman and Macpherson (1999), there is only oneway to learn, and that is by "doing it". The course gives students the opportunity to use and demonstrate the skills and experiences that they have developed during their time at University into a realistic and professional project situation."

"Finally, I feel that having a physical document that I can present to prospective employers is the most significant part of this project, because it shows plain and simple that I can plan, develop and produce this product."

Students are required to reflect on their own oral pitches and to provide written feedback on formal oral presentations to their peers. The students did this effectively, critically and constructively. Comments from students indicate they recommended the continuance of this as it helped them to be reflective and provided additional feedback beyond that of the convenor. Written assessment tasks included individual student aims for the course identified at the beginning of the semester, and a summative evaluation of those aims by the students at the end of semester.

Examples of student self evaluation include:

"At the beginning of the course, Field Project, my key learning objectives were to enhance my critical thinking and problem solving abilities, and to create innovative strategies, apply them to a project and evaluate these strategies to determine what was/n't successful. .... Overall, the assessment and guidance of Field Project has fostered my learning and encouraged me to reach the learning objectives I set myself at the beginning of the semester."

"I have enjoyed the creative learning in this course, it has made me understand 
the learnings and not only to memorize them. I have completed this course with a more indepth learning and understanding than when I started and will definitely use this for my future work."

"My critical evaluation skills have developed as well throughout the process - I have critiqued my work at every stage, looking for areas of improvement and enhancement."

"This course has helped me appreciate the need for analytical decision making using evidence based research and the requirements for strategic thinking."

"I feel that the presentations I did throughout this subject were the best I have done during my time at University, and this is possibly attributed to the professional approach taken."

An example of a reflection on peer feedback as well as an example of peer feedback follow:

"I have definitely learned a lot for future oral presentations and the use of peer review was unique and very beneficial; which I feel should be adopted in every course."

"No use of notes, good product knowledge and excellent use of visual aids to assist in selling the concept. Level tone of voice, good volume and addressed the whole group, answered questions well and professionally, kept the audience captivated by product knowledge. Needs to identify ethical issues as this is an important part of this course."

An overall reflection on the effectiveness of profession-based learning as a means to support students in 'becoming' tourism and hospitality professionals is now presented. All assessment tasks enabled students to build on previous submitted work. As a result, learning was sequential, feedback enables students to improve. This resulted in a greater number of students being awarded High Distinctions and Distinctions. All students were able to improve their final grades if they took on board the feedback, which was provided in a timely manner, usually within one week as each piece of assessment/learning was connected to the next. In first year of the action research project, students grade distributions were: HD (8) 12.1\%; D (23) $34.8 \%$; C (27) $40.9 \%$; P (7) $10.6 \%$; W (1) $1.5 \%$. In the second year, students grade distributions were: HD (11) $14.3 \%$; D (18) 23.4\%; C (21) 27.3\%; P (20) 26.0\%; PC (1) 1.3\%; SP (1) 1.3\%; F (4) 5.2\%. Student grade distributions for the third year were HD (2) $6.3 \%$; D (11) $34.4 \%$; C (15) 46.9\%; P (2) $6.3 \%$; F (2) $6.3 \%$.

Across the three years, students referred to the course as the most valuable, useful, extremely beneficial, or important phase of their studies. Students also valued that the course was tailored to their interests and the opportunity to 'think for themselves', which also related to personal reflections on independence. Students reflected on the different skills they gained or had enhanced during the Field Project course. These included presentations skills; communication skills; time management skills; research skills; problem solving skills; critical thinking and evaluating skills; as well as other skills, such as, how to hold a focus group, developing a concept or proposal, and general organisational skills. Students were 
also receptive to the value of ethics and responsible practice as well as sustainability issues associated with project work.

The final words with regard to the overall effectiveness of professionbased learning as a means to contextualise learning to support students in 'becoming' tourism and hospitality professionals are the students. Their words iterate the importance of transferring theory into practice. Additionally, their words resonate with those of Manorom \& Pollock, (2006; Bergquist \& Phillips, 1975) regarding complexity of professional practice as well as fun and enjoyment, respectively:

"Field Project allowed me to use academic skills I have learnt from previous courses and apply them to an actual event/situation. Through engaging with other students, projects, ideas and opinions this has helped me to develop essential graduate skills as I am hoping to graduate at the end of this semester. These skills involve effective communication, including oral and written and interpersonal, problem solving skills, the ability to work in teams, improve my innovative ability and creativity, and improve my understanding of responsible, effective citizenship."

"Greatly enjoyed the opportunity to finally put some kind of uni work into "actual" practice, have found that being in the industry since I was 14 has had a great advantage and it was refreshing to come across another course (other than food and beverage service) within my four year study that actually fulfilled those graduate learning skills. Thank-you".

"I can use the project as part of my future work portfolio."

"I will be using this project in my graduation portfolio to show my capabilities to apply theory into a practical situation."

\section{References}

Bergquist, W. H. \& Phillips, S. R. (1975). Getting students involved in the classroom. A handbook for faculty development, 114-7. Washington, DC: Council for the Advancement of Small Colleges.

Cambourne, B. (1984). The origins of teachers' doubts about 'naturalising' literacy education. And some suggestions for easing them. Reading: 1984 and Beyond, Selected Key Papers of the $10^{\text {th }}$ Australian Reading Conference 1984, Volume 2, pp. 17-39.

Errington, E. P. (1997). Role play. Canberra, ACT, Australia: HERDSA Green Guide.

Goodenough, R. A. \& S. J. Page (1993). Planning for tourism education and training in the 1990s: bridging the gap between industry and education, Journal of Geography in Higher Education, 17(1), 57-72. doi: 10.1080/03098269308709208

Heron, J. \& P. Reason (2008). Extending Epistemology within a Co-operative Inquiry. In: P. Reason \& Bradbury, H. (Eds.), The Sage Handbook of Action Research. 2nd ed., (pp. 366-380). London: Sage.

Jennings, G., Cater, C.I., Hales, R., Kensbock, S., and Hornby, G. (2015). Partnering for real world, learning, sustainability, tourism education, 
Quality Assurance in Education, 23(4), 378-394. doi: 10.1108/QAE-032015-0010

Jennings, G., Scantelbury, M., and K. Wolfe. (2009). Tertiary travel and tourism education: Using action research cycles to provide information on pedagogical applications associated with reflexivity, team-based learning and communities of practice. Journal of Teaching in Travel and Tourism, Vol. 9, Issues 3 \& 4, pp. 193-215.

Jennings, G.R., Hornby, G., Allen, G., Cater, C., Toohey, K., Richardson, S., \& M. Kennelly. (2007). Business ethics and responsible practice: A profession-based learning approach in tertiary education, paper presented at the Asia Pacific Academy of Business in Society, June, 2007, Port Vila, Vanuatu.

Kemmis, S. \& McTaggart, R. (1988). The action research planner. 3rd ed. Deakin University Press: Deakin University.

Lewin, K. (1948). Action research and minority problems. In K. Lewin. (Ed.), Resolving social conflicts. New York: Harper and Row.

Manorom, K \& Z. Pollock (2006). Role play as a teaching method: a practical guide. Ubon Ratchathani, Thailand: The Mekong Learning Initiative and the Mekong Sub-region Social Research Centre, Faculty of Liberal Arts, University of Ubon Ratchathani.

Ruhanen, L. (2006). Bridging the divide between theory and practice: experiential learning approaches for tourism and hospitality management education. Journal of Teaching in Travel and Tourism, 5(4), 33-51.

Taylor, H. (1999). Role-play cases for teaching interviewing skills in information systems analysis. Paper presented at HERDSA Annual International conference, July, 12-15, in Melbourne, Australia.

Vygotsky, L. S. (1978). Mind in society: The development of higher psychological processes (translated by M.M. Lopez-Mrillas Cole, A.R. Luria \& J. Wertsch. Cambridge, MA: Harvard

Wenger, E. (1998). Communities of practice: learning, meaning, and identity. Cambridge: Cambridge University Press. 